Research Article

\title{
Determination and Analysis of Trace Elements in Five Kinds of Traditional Chinese Medicine in High Blood Pressure Medicinal Food by ICP-AES
}

\author{
Li Yang $\mathbb{D}^{1}{ }^{1}$ Qinghua Yan $\mathbb{D}^{2},{ }^{2}$ Huixuan Zhang, ${ }^{2}$ and Jianwei Zhang ${ }^{1}$ \\ ${ }^{1}$ Department of Experimental Center, Henan Institute of Science and Technology, Xinxiang, Henan 453003, China \\ ${ }^{2}$ Department of Life Science and Technology, Xinxiang Medical University, Xinxiang, Henan 453003, China \\ Correspondence should be addressed to Li Yang; xkbhome@163.com
}

Received 29 July 2019; Revised 2 October 2019; Accepted 20 January 2020; Published 12 February 2020

Academic Editor: Jolanta N. Latosinska

Copyright ( 2020 Li Yang et al. This is an open access article distributed under the Creative Commons Attribution License, which permits unrestricted use, distribution, and reproduction in any medium, provided the original work is properly cited.

Objective. To establish a method for analysis of microelements in five kinds of traditional Chinese medicine in high blood pressure medicinal food, mainly including manganese, cobalt, selenium, iron, magnesium, and other 15 elements. Methods. The samples were digested using a microwave digestion instrument through $\mathrm{NHO}_{3}-\mathrm{H}_{2} \mathrm{O}_{2}$ solution, and then, the elements were synthesized by inductively coupled plasma atomic emission spectrometry (ICP-AES). Results. The content of cobalt, manganese, zinc, copper, and nickel in the high blood pressure diet foods is higher, the RSD is between $0.005 \%$ and $4.82 \%$, and the recovery rate ranges from $93.40 \%$ to $106.5 \%$. The precision and recovery of the detection method are higher. Conclusion. The experiment result is better. Medicinal foods curing high blood pressure contain a number of micronutrients that are beneficial to the human body. This experiment provides some meaningful basis for the prevention and treatment of cardiovascular diseases such as hypertension.

\section{Introduction}

High blood pressure has become a common disease in today's society, and the incidence of hypertension tends to be low, but the regimen is becoming a hot topic [1]. The key to preventing and relieving high blood pressure is proper diet. Medicinal food can be used to prevent and assist the treatment of high blood pressure; the raw materials are cheap and easy to obtain, the method is simple and convenient, the side effect is small, and the effect is persistent. Meanwhile, there are many kinds of constants and trace elements that are beneficial to the human body in Chinese medicines, such as haicao, yam, red date, wolfberry, and haw. In the human body, the amount of trace elements is small, but it is necessary to maintain the steady state of the body $[2,3]$. According to the study, trace elements, including minerals, regulate myocardial contraction and the components of the cell membrane, involved in cellular function, lipid control stability, antioxidation, regulation of blood pressure, and blood clotting. Thus, the disorder of trace elements can affect the synthesis of some enzymes and proteins, causing damage to the wall of the blood vessel and indirectly causing hypertension. Microelements also regulate blood pressure directly. So microelements have a close association with high blood pressure.

One of the traditional sample treatment methods in analysis of constants and trace elements is mainly wet digestion processing; the disadvantages of this approach is long digestion time, high sample consumption, and serious environmental pollution [4-6]. In recent years, microwave digestion technology has been widely used in almost every field of sample digestion processing, such as food, beverage, and human and animal organs for digestion; its advantages are mainly manifested in the low sample and reagent dosage, a short reaction time, and low environmental pollution [7-9]. Relative to atomic absorption spectrometry (AAS) and atomic fluorescence spectrophotometry, the inductively coupled plasma atomic emission spectrometry (ICP-AES) not only has obvious advantages in multielement analysis of the sample but also has simple analysis process, with low 
sample consumption, high sensitivity, accuracy, and rapidness [10-12]. When ICP-AES was used to analyze metal elements, the qualitative analysis of the metal elements in the sample is completed according to the characteristic wavelengths of different atomic emissions with low sample consumption. The quantitative analysis of the metal elements in the sample is performed according to the characteristic wavelength luminous intensity of different atomic emissions. The characteristic wavelength luminous intensity is related to the concentration of the element. In this experiment, the constants and trace elements of traditional Chinese medicine in high blood pressure medicinal food were tested by using microwave dissolution and ICP-AES method.

\section{Experimental}

2.1. Chemicals and Materials. $\mathrm{HNO}_{3}$ of superior grade of purity was obtained from Xilong Chemical Reagent Factory, and $\mathrm{H}_{2} \mathrm{O}_{2}$ of analysis grade of purity was obtained from Luoyang Haohua Chemical Co., Ltd. Concentrations of Ca, $\mathrm{Co}, \mathrm{Cu}, \mathrm{Fe}, \mathrm{K}, \mathrm{Mn}, \mathrm{Mg}, \mathrm{Na}$, and $\mathrm{Zn}$ were all $1000 \mu \mathrm{g} / \mathrm{mL}$ mixed standard stock solution (Merck of Germany), and concentrations of As, Cd, Cr, Ni, Pb, and Se were all $100 \mu \mathrm{g} / \mathrm{mL}$ mixed standard stock solution (Merck of Germany). Traditional Chinese medicinal plants such as coicin, yam, red date, wolfberry, and hawthorn were purchased from a Chinese medicine store in Xinxiang.

2.2. Instruments and Conditions. Optima 2100 DV inductively coupled plasma atomic emission spectrometry (ICPAES) device (PerkinElmer Corporation of USA), dual array solid-state CCD detector projection optical system, RYTON material atomizer, $40.68 \mathrm{MHz}$ solid-state high-frequency self-excited generator, polyscience circulating water cooling system, and MAS5 Microwave Digestion System (CEM Corporation of USA) were used in this study. ICP-AES operating parameters are shown in Table 1.

2.3. Compound Standard Solution. A proper amount of two mixed standard solutions was taken, and they were diluted separately with ultrapure water step by step. 0.50, 1.00, 2.00, 4.00 , and $8.00 \mu \mathrm{g} / \mathrm{mL}$ series of mixed standard solutions were prepared by using $1000 \mu \mathrm{g} / \mathrm{mL}$ mixed standard solutions. $0.25,0.50,1.00,2.00$, and $4.00 \mu \mathrm{g} / \mathrm{mL}$ series of mixed standard solutions were prepared by using $100 \mu \mathrm{g} / \mathrm{mL}$ mixed standard solutions.

2.4. Pretreatment of Experimental Materials. The medicinal material surface with was cleaned with water, then rinsed with distilled water 2 or 3 times, and then let to dry naturally. The medicine is pulverized into a powder form by using a pulverizer.

2.5. Experimental Process. $0.5 \mathrm{~g}$ of the accurately weighed material which has been crushed was placed into a digestion tank. $11 \mathrm{~mL}$ of $65-68 \%$ nitric acid and $1 \mathrm{~mL}$ of $30 \%$ hydrogen peroxide were added to each digestion tank. They are mixed evenly. The inner and outer lids of the microwave digestion tanks are covered. Then, the microwave digestion tanks are placed on the sample shelf which is then placed in the microwave digestion system. The operation procedure of the microwave digestion system is executed, and the samples are digested. The operational parameters of the microwave digestion are shown in Table 2 When the dissolving program is completed, the digested sample to is transferred to the corresponding beaker, and the beaker is placed on an electric heating plate under the temperature of $170^{\circ} \mathrm{C}$ in a fume hood. Heating is discontinued when the solution is about to boil away. The heated sample is then transferred to a $25 \mathrm{ml}$ volumetric flask and made up to $25 \mathrm{~mL}$ using ultrapure water.

2.6. Statistical Analysis. In this study, all calculations were performed in sextuplicate, and the data were reported as the mean \pm standard deviation (SD). Significant differences among mean values were analyzed by one-way analysis of variance (ANOVA) and Student's $t$-test. $P$ value $<0.05$ was considered statistically significant. All statistical analyses were performed with SPSS 20.0 (SPSS, Armonk, New York, USA).

\section{Results}

3.1. Choice of Microwave Digestion Conditions. Because of the strong polarity of nitric acid, $\mathrm{NHO}_{3}$ can break down the substrate and absorb microwaves well. It is often used as the preferred digestion solvent in the process of microwave digestion $[7,13]$. In order to improve the efficiency of digestion, $\mathrm{HClO}_{4}$ or $\mathrm{H}_{2} \mathrm{O}_{2}$ is often added as oxidants. Based on the strong acidity and the insecurity of $\mathrm{HClO}_{4}$, the $\mathrm{HNO}_{3}$ $\mathrm{H}_{2} \mathrm{O}_{2}$ system is often used in microwave digestion. The experimental results showed that $(11+1) \mathrm{mL}$ of $\mathrm{HNO}_{3}$ and $\mathrm{H}_{2} \mathrm{O}_{2}$ was used and the sample digestion was complete. After the digestion, the solution is clarified. The work parameters of the microwave apparatus will affect the digestion effect. The optimal digestion parameters are shown in Table 2.

\subsection{Analysis of Wavelength Selection and Background} Correction. Because the atomic structures of different elements are different, each element has its own several analysis wavelength in the ICP-AES analysis process. At the same time, the sensitivity of different wavelengths is completely different in the process of detecting elements. In order to improve the accuracy of the test results, 2-3 analysis wavelengths of different elements were selected for comparison and analysis; i.e., the wavelengths with high precision, less interference, and strong stability are selected. The analysis wavelengths of the elements are shown in Table 3.

3.3. Correlation Coefficient and Linear Equation. In order to obtain correlation coefficients and linear equations of all detected elements, each standard solution $x$ was detected three times by ICP-AES, and three signal intensity values $y 1$, 
TABLE 1: ICP-AES operating parameters.

\begin{tabular}{lccc}
\hline Power $(\mathrm{kW})$ & Auxiliary gas flow $(\mathrm{L} / \mathrm{min})$ & Cooling gas flow $(\mathrm{L} / \mathrm{min})$ & Carrier gas flow $(\mathrm{L} / \mathrm{min})$ \\
\hline 1.3 & 0.2 & 15.0 & 0.8 \\
\hline
\end{tabular}

TABLE 2: Operational parameters of the microwave digestion procedure.

\begin{tabular}{lcccc}
\hline Stage & Power $(\mathrm{W})$ & Temperature rise time $(\mathrm{min})$ & Running temperature $\left({ }^{\circ} \mathrm{C}\right)$ & Running time $(\mathrm{min})$ \\
\hline 1 & 1600 & 4 & 120 & 5 \\
2 & 1600 & 2 & 140 & 20 \\
\hline
\end{tabular}

TABLE 3: Analysis wavelengths of the element.

\begin{tabular}{lc}
\hline Element & Analysis wavelengths $(\mathrm{nm})$ \\
\hline $\mathrm{As}$ & 193.709 \\
$\mathrm{Ca}$ & 317.933 \\
$\mathrm{Cd}$ & 228.819 \\
$\mathrm{Co}$ & 228.616 \\
$\mathrm{Cr}$ & 267.739 \\
$\mathrm{Cu}$ & 327.418 \\
$\mathrm{Fe}$ & 238.222 \\
$\mathrm{~K}$ & 766.490 \\
$\mathrm{Mg}$ & 285.213 \\
$\mathrm{Mn}$ & 257.610 \\
$\mathrm{Na}$ & 589.592 \\
$\mathrm{Ni}$ & 231.604 \\
$\mathrm{~Pb}$ & 220.353 \\
$\mathrm{Se}$ & 196.026 \\
$\mathrm{Zn}$ & 213.871 \\
\hline
\end{tabular}

$y 2$, and $y 3$ were obtained at the same time. The average value $y$ of the three signal intensity values is automatically calculated through the instrument software (PerkinElmer Winlab32). Calibration curves and correlation coefficients of all test elements are obtained through the relationship between standard solution (the $x$ values) and intensity (the $y$ values) corresponding to their respective standard solutions [14]. The results are shown in Table 4.

It can be seen that the correlation coefficients of the elements were between 0.99771 and 0.9998 , which show that the standard curve of the linear relationship is better.

3.4. Measurement Results of the Samples. The digested solutions of all samples were tested under the best analytical line and background by ICP-AES. The measurement results are shown in Table 5.

It can be clearly seen that the concentrations of $\mathrm{K}, \mathrm{Ca}$, $\mathrm{Na}, \mathrm{Mg}$, and $\mathrm{Fe}$ were comparatively high among the trace elements in Table 5. The concentration order was $\mathrm{K}>\mathrm{Ca}>\mathrm{Na}>\mathrm{Mg}>\mathrm{Fe}>\mathrm{Zn}>\mathrm{Mn}>\mathrm{Cu}>\mathrm{Co}$. Wolfberry and coix seed were the richest sources of trace elements. Wolfberry contained the highest concentrations of $\mathrm{K}$ $(9806.00 \mu \mathrm{g} / \mathrm{g}), \mathrm{Na}(8986.00 \mu \mathrm{g} / \mathrm{g}), \mathrm{Fe}(109.65 \mu \mathrm{g} / \mathrm{g})$, and $\mathrm{Cu}$ $(14.70 \mu \mathrm{g} / \mathrm{g})$, while coix seed contained the highest concentration of $\mathrm{Mg}(1626.00 \mu \mathrm{g} / \mathrm{g}), \mathrm{Mn}(32.30 \mu \mathrm{g} / \mathrm{g}), \mathrm{Zn}$ $(54.45 \mu \mathrm{g} / \mathrm{g})$, and Se $(9.00 \mu \mathrm{g} / \mathrm{g})$. For $\mathrm{Zn}, \mathrm{Mn}$, and $\mathrm{Cu}$, their concentrations in the present study were higher in red dates $(16.50 \mu \mathrm{g} / \mathrm{g}, 11.5 \mu \mathrm{g} / \mathrm{g}$, and $6.70 \mu \mathrm{g} / \mathrm{g})$, wolfberry $(52.30 \mu \mathrm{g} / \mathrm{g}$,
TABLe 4: Correlation coefficients and linear equations of all elements.

\begin{tabular}{lcc}
\hline Element & Correlation coefficient & Linear equation \\
\hline $\mathrm{As}$ & 0.99865 & $y=6179 x-555$ \\
$\mathrm{Ca}$ & 0.99990 & $y=318900 x-15372.1$ \\
$\mathrm{Cd}$ & 0.99998 & $y=36000 x+7163.8$ \\
$\mathrm{Co}$ & 0.99979 & $y=76280 x-5313$ \\
$\mathrm{Cr}$ & 0.99998 & $y=321700 x-5064.4$ \\
$\mathrm{Cu}$ & 0.99990 & $y=521400 x-25491.7$ \\
$\mathrm{Fe}$ & 0.99991 & $y=399000 x-18038$ \\
$\mathrm{~K}$ & 0.99824 & $y=866700 x-178226.6$ \\
$\mathrm{Mg}$ & 0.99989 & $y=883600 x-44137.4$ \\
$\mathrm{Mn}$ & 0.99992 & $y=3203000 x-133629.7$ \\
$\mathrm{Na}$ & 0.99876 & $y=2733000 x-470426.3$ \\
$\mathrm{Ni}$ & 0.99998 & $y=140400 x-2841.6$ \\
$\mathrm{~Pb}$ & 0.99778 & $y=29200 x-3370.3$ \\
$\mathrm{Se}$ & 0.99771 & $y=2865 x-336.4$ \\
$\mathrm{Zn}$ & 0.99997 & $y=276300 x-6079.3$ \\
\hline
\end{tabular}

$12.95 \mu \mathrm{g} / \mathrm{g}$, and $14.70 \mu \mathrm{g} / \mathrm{g})$, and coix seed $(54.45 \mu \mathrm{g} / \mathrm{g}$, $32.30 \mu \mathrm{g} / \mathrm{g}$, and $7.65 \mu \mathrm{g} / \mathrm{g}$ ) than shown in the results of the literature by Khan and Zhang et al. $(7.86-23.88 \mu \mathrm{g} / \mathrm{g}$, $9.21-19.66 \mu \mathrm{g} / \mathrm{g}$, and $2.80-13.90 \mu \mathrm{g} / \mathrm{g})$, respectively [15-17]. The $\mathrm{Zn}(17.55 \mu \mathrm{g} / \mathrm{g})$ and $\mathrm{Cu}(9.35 \mu \mathrm{g} / \mathrm{g})$ contents in yam were higher in comparison with the published data by Cônsolo and Zhuang et al. $[18,19]$, while the $\mathrm{Fe}(42.65 \mu \mathrm{g} / \mathrm{g})$ content was lower in comparison with the published data by Shin and Cônsolo et al. $[18,20]$. In wolfberry, the $\mathrm{Zn}(52.30 \mu \mathrm{g} / \mathrm{g})$ and $\mathrm{Mn}(12.95 \mu \mathrm{g} / \mathrm{g})$ contents found in the present work were close to the levels found in the literature by Zeiner $(13.80-21.10 \mu \mathrm{g} / \mathrm{g}, 9.21-11.27 \mu \mathrm{g} / \mathrm{g})$ [21]. The Fe $(109.65 \mu \mathrm{g} / \mathrm{g})$ concentration was much higher and the $\mathrm{Mg}(842.00 \mu \mathrm{g} / \mathrm{g})$ concentration was much lower than those in the literature. The Cr $(3.75 \mu \mathrm{g} / \mathrm{g})$ and Co $(6.70 \mu \mathrm{g} / \mathrm{g})$ contents of red dates and hawthorn were much higher than those in the literature $(0.11-0.17 \mu \mathrm{g} / \mathrm{g}$ and $0.02-0.16 \mu \mathrm{g} / \mathrm{g})[15,21]$. In coix seeds, the $\mathrm{Fe}(42.65 \mu \mathrm{g} / \mathrm{g}), \mathrm{Mn}(32.30 \mu \mathrm{g} / \mathrm{g})$, and $\mathrm{Ca}(178.90 \mu \mathrm{g} / \mathrm{g})$ contents were close to the levels given in the literature [16], while the $\mathrm{Pb}(7.48 \mu \mathrm{g} / \mathrm{g})$ concentration was higher and the $\mathrm{Cd}$ concentration was lower than those given in the literature by Cônsolo and Zhang $[16,18]$.

3.5. Accuracy and Recovery of the Determination Method. The RSD calculated from the data of the six iterations was between $0.005 \%$ and $4.82 \%$, respectively, both within the range required by the precision. To test the performance of 
TABLE 5: Measurement results of samples.

\begin{tabular}{lccccc}
\hline Element & Red dates & Wolfberry & Hawthorn & Yam & Coix seed \\
\hline $\mathrm{As}$ & $5.20 \pm 0.043$ & $4.20 \pm 0.061$ & $4.45 \pm 0.062$ & $5.05 \pm 0.094$ & $4.70 \pm 0.041$ \\
$\mathrm{Ca}$ & $750.00 \pm 9.83$ & $821.00 \pm 8.14$ & $1140.00 \pm 37.23$ & $1326.00 \pm 14.65$ & $178.90 \pm 4.68$ \\
$\mathrm{Cd}$ & Not detected & Not detected & Not detected & Not detected & Not detected \\
$\mathrm{Co}$ & $7.75 \pm 0.047$ & $6.80 \pm 0.085$ & $6.15 \pm 0.018$ & $5.70 \pm 0.073$ & $6.90 \pm 0.052$ \\
$\mathrm{Cr}$ & $3.75 \pm 0.056$ & $4.00 \pm 0.039$ & $3.70 \pm 0.081$ & $4.35 \pm 0.086$ & $4.25 \pm 0.068$ \\
$\mathrm{Cu}$ & $6.70 \pm 0.033$ & $14.70 \pm 0.098^{*}$ & $8.05 \pm 0.064$ & $9.35 \pm 0.087$ & $7.65 \pm 0.088$ \\
$\mathrm{Fe}$ & $27.00 \pm 0.86$ & $109.65 \pm 2.45^{*}$ & $54.40 \pm 1.67$ & $87.50 \pm 2.83$ & $42.65 \pm 1.67$ \\
$\mathrm{~K}$ & $6425.00 \pm 24.68$ & $9806.00 \pm 28.91^{*}$ & $7975.00 \pm 27.18$ & $6540.00 \pm 22.93$ & $3379.00 \pm 18.17$ \\
$\mathrm{Mg}$ & $322.95 \pm 2.14$ & $842.00 \pm 3.28$ & $783.00 \pm 3.97$ & $666.00 \pm 2.88$ & $1626.00 \pm 17.84^{\#}$ \\
$\mathrm{Mn}$ & $11.50 \pm 0.098$ & $12.95 \pm 0.079$ & $7.90 \pm 0.058$ & $8.00 \pm 0.049$ & $32.30 \pm 1.21^{\#}$ \\
$\mathrm{Na}$ & $678.00 \pm 7.49$ & $8986.00 \pm 26.97^{*}$ & $426.55 \pm 4.38$ & $964.00 \pm 5.29$ & $298.05 \pm 3.78$ \\
$\mathrm{Ni}$ & $6.45 \pm 0.082$ & $5.70 \pm 0.069$ & $5.10 \pm 0.047$ & $4.75 \pm 0.058$ & $6.40 \pm 0.068$ \\
$\mathrm{~Pb}$ & $7.35 \pm 0.093$ & $7.60 \pm 0.055$ & $7.95 \pm 0.072$ & $7.45 \pm 0.048$ & $7.85 \pm 0.068$ \\
$\mathrm{Se}$ & $7.50 \pm 0.073$ & $7.85 \pm 0.054$ & $8.85 \pm 0.066$ & $7.65 \pm 0.082$ & $9.00 \pm 0.074^{\#}$ \\
$\mathrm{Zn}$ & $16.15 \pm 0.088$ & $52.30 \pm 1.24$ & $19.20 \pm 0.094$ & $17.55 \pm 0.058$ & $54.45 \pm 1.95^{\#}$ \\
\hline
\end{tabular}

${ }^{*} P<0.05$, wolfberry group vs other groups; ${ }^{\#} P<0.05$, coix seed group vs other groups.

the established method, the spike experiment was performed through the spiking hawthorn sample. Three quantitative levels of the analytes spiked were controlled according to $80 \%$ base value, $100 \%$ base value, and $120 \%$ base value of the hawthorn sample, respectively. Each test solution was analyzed in six replicates. Meanwhile, the detected amounts of three analytes were calculated based on the corresponding calibration curves. The spike recovery rates were calculated by using the following equation: spike recovery $(\%)=($ total amount detected - amount original)/amount spiked $\times 100 \%$. According to the results of spike recovery, the recovery rates of the elements were between $93.40 \%$ and $106.5 \%$, which accorded with the experimental requirements. Table 6 shows the results of RSD and spike recovery experiments for each element detected in hawthorn.

It is concluded that the experimental method of detecting 5 kinds of commonly used traditional Chinese medicine in high blood pressure diet is higher and the accuracy is good, which meets the requirements of analysis.

\section{Discussion}

Trace elements are important factors in maintaining a steady state, and they take part in many metabolic processes in the body. Numerous studies have shown that the imbalance of 35 elements such as $\mathrm{Co}, \mathrm{Zn}, \mathrm{Cr}$, and $\mathrm{Mn}$ is related to the occurrence and development of cerebral blood vessels in the heart. The key to cardiovascular disease such as hypertension is the balance of diet. The experiment found that the Chinese native medicine ingredients of hypertension medicinal food contain many elements, which are beneficial to the metabolism, can well balance the metabolic hypertension activity of patients, and can maintain the steady state and recuperate body health.

4.1. $\mathrm{Ca}$. The level of $\mathrm{Ca}$ in serum is a significant factor in regulation of blood pressure. The study found that high blood pressure patients had higher levels of $\mathrm{Ca}$ and $\mathrm{Na}$ in their serum than normal patients [22]. The higher levels of $\mathrm{Ca}$ in the serum of high blood pressure patients stimulate blood vessels to contract, increase the release of renin and catecholamine, and interact with the sympathetic nerve, which leads to metabolic of the neurotransmitter disorders. But some studies have found that if you consume less than $300 \mathrm{mg}$ of $\mathrm{Ca}$ a day, there is a 15 percent chance to have high blood pressure. The epidemiological association of animal studies showed that people with primary hypertension had low levels of $\mathrm{Ca}$ in their serum. So a modest quantity of Ca supplements is good for the heart. Its mechanism is to participate in the synthesis of the structural protein of the blood vessel cells and maintain the balance of $\mathrm{Na}$ and $\mathrm{K}$ in the cell.

4.2. Co. Co is involved in the synthesis of vitamin B12, and its main function is to be involved in hematopoiesis. One of the reasons for the occurrence of megaloblastic anemia is the lack of vitamin B12 or cobalt. Low levels of cobalt in the serum of hypertensive patients may affect the metabolism of amino acids linked to high blood pressure. A lack of Co can lead to production of homocysteine, which is one of the causes of hypertension [23]. Because the methionine synthetase contains cobalt, when the Co content is insufficient, methionine synthetase during the transfer of methyl group cannot effectively convert homocysteine, thus leading to homocysteine deposition in the body.

4.3. $\mathrm{Cr}$. $\mathrm{Cr}$ is the constituent of chromatin. GTF is made up of four amino acid polypeptides combined with four $\mathrm{Cr}^{4+}$. Animal studies have shown that $\mathrm{Cr}$ is a useful element in the cardiovascular system. $\mathrm{Cr}$ can regulate lipid metabolism and mainly increase high-density lipoprotein, prompt the cholesterol to transport to the liver, accelerate the metabolism of cholesterol, and prevent atherosclerosis. $\mathrm{Cr}$ involves in the synthesis of more amount of insulin and its receptors. Inadequate intake of $\mathrm{Cr}$ can effectively reduce the level of insulin. As a result, blood glucose in the body is not fully utilised, which makes the body susceptible to hypertension. At the same time, due to the degradation of insulin receptors, insulin starts accumulating in the body. As a result, 
TABLE 6: Accuracy and recovery of determination method.

\begin{tabular}{|c|c|c|c|c|c|}
\hline Element & RSD (\%) & Base value & Quantity added & Quantity found & Recovery (\%) \\
\hline As & 0.41 & 4.45 & 5.00 & 9.12 & 93.40 \\
\hline $\mathrm{Ca}$ & 3.75 & 1140.00 & 1100.00 & 2255.00 & 101.36 \\
\hline $\mathrm{Cd}$ & Not detected & Not detected & 10.00 & 9.40 & 94.00 \\
\hline $\mathrm{Co}$ & 4.35 & 6.15 & 6.00 & 11.96 & 96.83 \\
\hline $\mathrm{Cr}$ & 1.16 & 3.70 & 4.00 & 7.50 & 95.00 \\
\hline $\mathrm{Cu}$ & 1.21 & 8.05 & 10.00 & 17.96 & 99.10 \\
\hline $\mathrm{Fe}$ & 2.49 & 54.40 & 50.00 & 103.30 & 97.80 \\
\hline $\mathrm{K}$ & 1.46 & 7975.00 & 8000.00 & 15989.00 & 100.18 \\
\hline $\mathrm{Mg}$ & 2.53 & 783.00 & 800.00 & 1567.00 & 98.00 \\
\hline $\mathrm{Mn}$ & 0.006 & 7.90 & 8.00 & 15.20 & 91.25 \\
\hline $\mathrm{Na}$ & 0.96 & 426.55 & 400.00 & 836.87 & 102.08 \\
\hline $\mathrm{Ni}$ & 4.82 & 5.10 & 5.00 & 9.87 & 95.40 \\
\hline $\mathrm{Pb}$ & 1.09 & 7.95 & 8.00 & 15.63 & 96.00 \\
\hline $\mathrm{Se}$ & 4.07 & 8.85 & 10.00 & 18.26 & 94.10 \\
\hline $\mathrm{Zn}$ & 3.95 & 19.20 & 20.00 & 40.06 & 104.30 \\
\hline
\end{tabular}

the more amount of insulin prevents degradation of fat materials, blood triglycerides, which further intensifies hypertension [24].

4.4. $\mathrm{Cu}$. $\mathrm{Cu}$ is the co-gene of collagen and elastin synthase lysine oxidase. In the early stages of atherosclerosis, collagen and elastin change in quality and quantity. The lack of copper causes the activity of lysine oxidase to decrease, and the production of collagen and elastin is not sufficient, causing the wall of the vessel to become brittle and vulnerable to damage. The cells in the area around the lesion proliferate, and there is a buildup of connective tissues and fat in the lesion, slowly forming atherosclerosis, which affects the regulation of blood pressure. $\mathrm{Cu}^{2+}$ is also found in superoxide dismutase showing antioxidant properties. $\mathrm{Cu}$ is also involved in the metabolism of tyrosine and dopamine, a precursor of norepinephrine, which can be removed by norepinephrine. When the body is deprived of copper, superoxide anions are converted to oxide peroxides which affect the activity of enzymes and hormones. This in turn causes brain artery atherosclerosis, increases the risk of cerebral hemorrhage, and also affects the regulation of blood pressure. The decrease in copper content also lowers the activity of the phosphoester-cholesterol acyl transferase, blocks the cholesterol conversion, increases the cholesterol level, and increases the risk of high blood pressure [25].

4.5. Fe. A study has found that people with high blood pressure have higher levels of serum iron than in a healthy person. Oxidation of free iron damages DNA, proteins, and hormones and causes other inactivation. The main causes of high blood pressure are as follows: (1) peroxidation of lipids and damage of vascular endothelial cells; (2) the transformation of arterial smooth muscle of low-density lipoprotein. $\mathrm{Fe}$ is mainly combined with hemoglobin [26]. If the body's iron content is exorbitant, hemoglobin level will also rise, the viscosity of red blood cells increases, and the regulation of blood pressure is highly influenced.
4.6. $\mathrm{Mg}$. $\mathrm{Mg}$ is a one of the important trace elements and is high in the heart muscle. Mg deficiency leads to cardiovascular effects such as myocardial calcification, atherosclerosis, thrombosis, hypertension, coronary heart disease, high cholesterol, high triglycerides, abnormal lipoprotein, and cell membrane permeability and liquidity increase [27]. $\mathrm{Mg}$ can lower blood pressure, and large doses of magnesium can expand the blood vessels. $\mathrm{Mg}$ is involved in regulating blood lipids and preventing atherosclerosis. In the mitochondria, magnesium ions in Na-K-ATPase and phosphates react under the catalysis of Mg-ATP. This leads to activation of adenylate cyclase, causes oxidative phosphorylation in the sarcoplasmic reticulum, causes release of calcium ions, combined with $\mathrm{Ca}^{2+}$ ATPase, regulates the internal flow of extracellular $\mathrm{Na}^{+}$, and regulates myocardial contraction. $\mathrm{Mg}$ can also maintain the permeability and fluidity of the cell membrane, maintain the balance of $\mathrm{Na}$ and $\mathrm{K}$ in the cell, and maintain stability of the heart rate. $\mathrm{Mg}$ also has antioxidant property, can compete with Fe in cells, can reduce the iron content in cells, thereby reducing intracellular iron oxidative damage in cells, and is also the agent of antioxidant activity, showing antioxidant effect. The magnesium content of Chinese traditional medicine for high blood pressure is generally higher, which can play a role in lowering blood pressure.

4.7. $\mathrm{Mn}$. $\mathrm{Mn}$ is a common trace element and is involved in the antiradical reaction. $\mathrm{Mn}$ is an active ingredient of superoxide dismutase, which can be used to combat oxidative damage to blood vessels [28]. Mn is essential in the metabolism of synthetic vitamins B, C, and E, fat, and protein. Mn also regulates blood sugar through phosphorylation and redox reaction. Studies have found that $\mathrm{Mn}$ is negatively correlated with blood pressure, suggesting that a lack of manganese may increase the risk of high blood pressure. Mn may be a protective factor for blood pressure. $\mathrm{Mn}$ is a special blocker of calcium-ion channels, which blocks the excitation-contraction coupling of the smooth muscle of the blood vessel, which then reduces blood pressure. 
4.8. Ni. Ni is a necessary micronutrient for the human body and is involved in maintaining the stability and metabolism of biological molecules [29]. Ni is a component of insulin that affects blood sugar regulation. Lack of $\mathrm{Ni}$ can lead to stunting growth, severe anemia, diabetes, uremia, cirrhosis, and other diseases. Lack of $\mathrm{Ni}$ can lead to myocardial electrolyte disturbance $(\mathrm{Na}, \mathrm{Cl}, \mathrm{K}$, and $\mathrm{Ca}$ ) and affect the conduction function of the myocardium. High nickel leads to ischemic myocardial cells, myocardial mitochondria membrane damage, increased coronary artery spasm, worsening of coronary ischemia condition, damage of myocardial cells, and inducing the occurrence of coronary heart disease.

4.9. Se. Se is the active form of selenocysteine, which is found in nearly 30 proteins in the body. These proteins, known as selenium proteins, mainly include glutathione peroxidase(GSP-Px), selenoprotein $\mathrm{P}$, thioredoxin reductase, and Iodine armour gland original glycine II. Se plays an important role in the regulation of hypertension. Se forms the active center of GSP-Px in the form of selenocysteine. GSP-Px can turn the peroxide of the oxidative cell membrane into a harmless hydroxy compound. At the same time, the GSP-Px also strengthens the antioxidant effect of vitamin E, which protects cell membranes with vitamin $\mathrm{E}$. The main function of selenium protein $\mathrm{P}$ is to transfer selenium to its target tissues and target organs. The lack of Se can cause many diseases such as diabetes, cardiovascular disease, neurodegenerative diseases, and certain cancers. It was found in animal experiments that selenium can enhance the activity of sodium-calcium pump in spontaneously hypertensive rats, increase the level of nitric oxide(a vasodilator), and improve hypertension [30]. Se can also be converted into a selenium enzyme, which can dissolve the cholesterol during blood vessel damage and unclog the blood vessels.

4.10. $\mathrm{Zn}$. People with high blood pressure have low levels of $\mathrm{Zn}$, suggesting that $\mathrm{Zn}$ deficiency may lead to high blood pressure [31]. The regulation mechanism of $\mathrm{Zn}$ for blood pressure is as follows: $\mathrm{Zn}$ is a component of membrane lipoproteins and is involved in the formation of endothelial cells. In the renin-angiotensin system, $\mathrm{Zn}$ regulates the activity of angiotensin-converting enzyme, lowering blood pressure. High blood pressure may be associated with immunity, and $\mathrm{Zn}$ as an immune-regulating agent may relieve the symptoms of hypertension in older age. It is involved in the composition of copper-zinc superoxide dismutase, eliminating oxygen-free radicals and preventing atherosclerosis of cerebral blood vessels.

\section{Conclusions}

The ICP-AES method can also be used to detect the common trace elements of traditional Chinese medicine in hypertension diet. This method has high precision and good accuracy, and the measurement result is satisfactory. Among the selected Chinese medicines, the content of $\mathrm{Ca}, \mathrm{Cu}, \mathrm{Zn}$, $\mathrm{Mg}, \mathrm{Cr}$, Se, $\mathrm{Co}$, and $\mathrm{Mg}$ is high, indicating that these elements have a positive effect on the treatment and prevention of hypertension. The contents of $\mathrm{Fe}$ and $\mathrm{Ni}$ which have a negative effect on hypertension are not too high. Hazardous elements such as $\mathrm{As}$ and $\mathrm{Pb}$ are less, and $\mathrm{Cd}$ is not detected. This article for the dietary method to prevent and adjust treatment of hypertension provides a certain guiding role.

\section{Data Availability}

The data used to support the findings of this study are included within the article.

\section{Conflicts of Interest}

The authors declare that there are no conflicts of interest associated with this work.

\section{Acknowledgments}

The authors are thankful to financial support obtained from the project of training young backbone teachers in Key Scientific Research Projects of Higher Education Institutions of Henan Province (20A180002), Henan College of Higher Education (Grant No. 2017GGJS221), Science and Technology Research and Development Project of Henan Province in 2019 (Grant No. 192102310249), Key R\&D and promotion projects in Henan province in 2019, China Postdoctoral Science Foundation (Grant No. 2017M622341), 2016 high-level talent research project of Henan Institute of Science and Technology (304010617001), and Henan Postdoctoral Science Foundation and Funding for Postdoctoral Research Projects.

\section{References}

[1] L. Toxqui, R. Blanco-Rojo, I. Wright, A. Pérez-Granados, and M. Vaquero, "Changes in blood pressure and lipid levels in young women consuming a vitamin D-fortified skimmed milk: a randomised controlled trial," Nutrients, vol. 5, no. 12, pp. 4966-4977, 2013.

[2] N. Zahra, K. Imran, M. Minahil, and N. Nageen, "Perilous effects of heavy metals contamination on human health," Pakistan Journal of Analytical \& Environmental Chemistry, vol. 18, no. 1, pp. 1-17, 2017.

[3] T. H. Lim, T. Sargent, and N. Kusubov, "Kinetics of trace element chromium (III) in the human body," American Journal of Physiology-Regulatory, Integrative and Comparative Physiology, vol. 244, no. 4, pp. 445-454, 1983.

[4] P. Sangmanee, B. Dell, R. J. Harper, and D. J. Henry, "Quantification of deep soil carbon by a wet digestion technique,” Soil Research, vol. 55, no. 1, pp. 78-85, 2017.

[5] O. Acar, A. Tunçeli, and A. R. Türker, "Comparison of wet and microwave digestion methods for the determination of copper, iron and zinc in some food samples by FAAS," Food Analytical Methods, vol. 9, no. 11, pp. 3201-3208, 2016.

[6] L. Luning, E. H. M. van Zundert, and A. J. F. Brinkmann, "Comparison of dry and wet digestion for solid waste," Water Science \& Technology, vol. 48, no. 4, pp. 15-20, 2015.

[7] G. Habte, J. Y. Choi, E. Y. Nho et al., "Determination of essential and toxic elements in tropical fruit by microwave-assisted 
digestion and inductively coupled plasma-mass spectrometry," Analytical Letters, vol. 50, no. 6, pp. 1025-1039, 2017.

[8] E. Lehtimäki and A. Väisänen, "Determination of metal concentrations in certified plastic reference materials after small-size autoclave and microwave-assisted digestion followed with inductively coupled plasma optical emission spectrometry," Spectrochimica Acta Part B: Atomic Spectroscopy, vol. 127, pp. 64-69, 2017.

[9] S. Kilic, "Survey of trace elements in bottled natural mineral waters using ICP-MS," Environmental Monitoring and Assessment, vol. 191, no. 7, p. 452, 2019.

[10] A. Sengupta, R. H. Sankhe, and V. Natarajan, "Rapid and nondestructive determination of uranium and thorium by gamma spectrometry and a comparison with ICP-AES," Journal of Radioanalytical and Nuclear Chemistry, vol. 306, no. 2, pp. 401-406, 2015.

[11] X. L. Chen, M. B. Morewane, X. Z. Xue, W. Z. Guo, and L. C. Wang, "Analysis of inorganic elements in hydroponic taraxacum mongolicum grown under different spectrum combinations by ICP-AES," Spectroscopy and Spectral Analysis, vol. 35, no. 2, pp. 519-522, 2015.

[12] M. Safari, Y. Yamini, M. Y. Masoomi, A. Morsali, and A. Mani-Varnosfaderani, "Magnetic metal-organic frameworks for the extraction of trace amounts of heavy metal ions prior to their determination by ICP-AES," Microchimica Acta, vol. 184, no. 5, pp. 1555-1564, 2017.

[13] Q. Yan, Y. Liu, and L. Yang, "Analysis of essential and toxic elements in jujube fruits collected from different locations in China," Tropical Journal of Pharmaceutical Research, vol. 13, no. 4, pp. 607-611, 2014.

[14] A. G. Asuero, A. Sayago, and A. G. González, "The correlation coefficient: an overview," Critical Reviews in Analytical Chemistry, vol. 36, no. 1, pp. 41-59, 2006.

[15] N. Khan, N. Jamila, Y. MiDang et al., "Elemental analysis of stone fruits by inductively coupled plasma-mass spectrometry and direct mercury analysis," Analytical Letters, vol. 50, no. 15, pp. 2426-2446, 2017.

[16] L. Zhang, X. Y. Nie, and A. Le, "Rapid determination of 15 metallic elements in 2 kinds of coix seeds by inductively coupled plasma-mass spectrometry after closed-vessel microwave digestion," Journal of Food Process Engineering, vol. 40, no. 5, Article ID e12528, 2017.

[17] S. Zhang, Y. Wei, S. Wei, H. Liu, and B. Guo, "Authentication of Zhongning wolfberry with geographical indication by mineral profile," International Journal of Food Science \& Technology, vol. 52, no. 2, pp. 457-463, 2017.

[18] F. Z. Cônsolo, P. Melnikov, Z. Lourdes Zanoni, J. Rimoli, A. F. da Silva, and V. A. do Nascimento, "Magnesium, iron, copper and zinc in vegetable roots from Mato Grosso do Sul, Brazil," Orbital: The Electronic Journal of Chemistry, vol. 9, no. 3, pp. 135-139, 2017.

[19] P. Zhuang, M. B. McBride, H. Xia, N. Li, and Z. Li, "Health risk from heavy metals via consumption of food crops in the vicinity of Dabaoshan mine, South China," Science of the Total Environment, vol. 407, no. 5, pp. 1551-1561, 2009.

[20] M.-Y. Shin, Y.-E. Cho, C. Park, H.-Y. Sohn, J.-H. Lim, and I.-S. Kwun, "The supplementation of yam powder products can give the nutritional benefits of the antioxidant mineral $(\mathrm{Cu}, \mathrm{Zn}, \mathrm{Mn}, \mathrm{Fe}$ and $\mathrm{Se})$ intakes," Preventive Nutrition and Food Science, vol. 17, no. 4, pp. 299-305, 2012.

[21] M. Zeiner, I. Juranović Cindrić, D. Mihajlov Konanov, and G. Stingeder, "Determination of selected toxic elements in leaves of white hawthorn grown in a remote area," E3S Web of Conferences, vol. 1, p. 34003, 2013.
[22] T. Kishimoto, T. Tanaka, and Y. Fukuzawa, "The relationship of hair Ca nad Mg TO blood pressure in high school students," Biomedical Research on Trace Elements, vol. 2, pp. 131-132, 1991.

[23] L. L. Lima, T. M. M. Moreira, and M. S. B. Jorge, "Produção do cuidado a pessoas com hipertensão arterial: acolhimento, vínculo e corresponsabilização," Revista Brasileira de Enfermagem, vol. 66, no. 4, pp. 514-522, 2013.

[24] N. H. Buus, M. J. Mulvany, H. Eiskjær, K. L. Christensen, and K. Skov, "Renal resistance and long-term blood pressure in individuals genetically predisposed for essential hypertension," Journal of Hypertension, vol. 34, no. 6, pp. 1170-1177, 2016.

[25] A. Justice, S. Essien-Baidoo, E. Ofori, and A. Abaka-Yawson, "Trace elements levels and blood pressure in ghanaian women using depot medroxyprogesterone scetate contraceptive," British Journal of Medicine and Medical Research, vol. 20, no. 11, pp. 1-7, 2017.

[26] S. Y. Yang, C. B. Lan, C. H. Chen et al., "Independency of Fe ions in hemoglobin on immunomagnetic reduction assay," Journal of Magnetism and Magnetic Materials, vol. 321, no. 19, pp. 3266-3269, 2009.

[27] M. A. Burton, C. S. Nilank, J. S. Gatha et al., "Short-term Mg deficiency upregulates protein kinase $\mathrm{C}$ isoforms in cardiovascular tissues and cells; relation to NF- $\kappa \mathrm{B}$, cytokines, ceramide salvage sphingolipid pathway and PKC-zeta: hypothesis and review," International Journal of Clinical and Experimental Medicine, vol. 7, no. 1, pp. 1-21, 2014.

[28] M. Zanetti, J. Sato, C. J. Jost, P. Gloviczki, Z. S. Katusic, and T. O'Brien, "Gene transfer of manganese superoxide dismutase reverses vascular dysfunction in the absence but not in the presence of atherosclerotic plaque," Human Gene Therapy, vol. 12, no. 11, pp. 1407-1416, 2001.

[29] J. Piovár, M. Weidinger, M. Bačkor, M. Bačkorová, and I. Lichtscheidl, "Short-term influence of $\mathrm{Cu}, \mathrm{Zn}, \mathrm{Ni}$ and $\mathrm{Cd}$ excess on metabolism, ultrastructure and distribution of elements in lichen Xanthoria parietina (L.) Th. Fr.," Ecotoxicology and Environmental Safety, vol. 145, pp. 408-419, 2017.

[30] C. Tsioufis, D. Tsiachris, K. Dimitriadis et al., "Evidence for no global effect of metabolic syndrome per se on early hypertensive sequelae," Journal of Hypertension, vol. 26, no. 4, pp. 773-779, 2008.

[31] L. J. Rondón, E. Marcano, F. Rodríguez, and J. R. del Castillo, "Blood pressure, magnesium and other mineral balance in two rat models of salt-sensitive, induced hypertension: effects of a non-peptide angiotensin II receptor type 1 antagonist," Magnesium Research, vol. 27, no. 3, pp. 113-130, 2014. 